\title{
Calcined biomass-modified bentonite clay for removal of aqueous metal ions
}

\author{
Bamidele I. Olu-Owolabi ${ }^{\mathrm{a}}$, Alimoh H. Alabi ${ }^{\mathrm{a}, *}$, Emmanuel I. Unuabonah $^{\mathrm{b}}$, \\ Paul N. Diagboya ${ }^{\mathrm{c}}$, Leonard Böhm ${ }^{\mathrm{d}}$, Rolf-Alexander Düring ${ }^{\mathrm{d}}$ \\ a Department of Chemistry, University of Ibadan, Ibadan, Nigeria \\ ${ }^{\mathrm{b}}$ College of Natural Sciences, Department of Chemical Sciences, Redeemer's University, Ogun State, Nigeria \\ ${ }^{\mathrm{c}}$ Landmark University, Omu-Aran, Kwara State, Nigeria \\ ${ }^{\mathrm{d}}$ Institute of Soil Science and Soil Conservation, Justus Liebig University, Giessen, Germany
}

\section{A R T I C L E I N F O}

\section{Article history:}

Received 2 November 2015

Received in revised form 25 January 2016

Accepted 31 January 2016

Available online 2 February 2016

\section{Keywords:}

Carica papaya seed

Pine cone

Bentonite

Calcination

Biomass-modified clay

Metals

\begin{abstract}
A B S T R A C T
Recent studies have shown that kaolinite clay modified with biosorbents are promising low cost adsorbents for the removal of metals from aqueous solution because the resultant composites have higher adsorption capacities, and hence a better aqueous metal ions removal efficiencies. However, some clay properties suggest that not all such modifications enhance adsorption capacity. In this study, bentonite (BEN) clay was calcined after modification with Carica papaya seeds or pine cone to obtain $C$. papaya-modified bentonite ( $\mathrm{CPB}$ ) and pine cone-modified bentonite (PCB). The efficiencies of these adsorbents for the removal of $\mathrm{Pb}(\mathrm{II}), \mathrm{Cu}(\mathrm{II})$ and $\mathrm{Cd}(\mathrm{II})$ ions from aqueous solutions were studied as a function of $\mathrm{pH}$, time, sorbate concentration and temperature. X-ray diffraction results showed that CPB and PCB had lattice structure as BEN, but reductions in the surface areas of CPB and PCB were observed. Adsorption results showed that $\mathrm{pH}$ did not significantly affect removal of aqueous metal ions between $\mathrm{pH}$ 3 and 7. The adsorption fitted pseudo-second order $\left(r^{2} \geq 0.966\right)$ and intra-particle diffusion models and indicated mainly surface phenomena involving sharing of electrons between the adsorbent surfaces and the metal ion species. Unlike $\mathrm{Cu}$ (II) and $\mathrm{Cd}(\mathrm{II}), \mathrm{Pb}(\mathrm{II})$ adsorption reduced in $\mathrm{CPB}$ and PCB indicating that not all calcined biomass-clay composites have enhanced aqueous metal adsorption efficiency. However, undesired properties such as adsorbent bleeding were removed and mechanical strength enhanced while easier separation of the adsorbents from solution as compared to the raw bentonite was observed.
\end{abstract}

(c) 2016 Elsevier Ltd. All rights reserved.

\section{Introduction}

The search for cheap, efficient and accessible water treatment technologies cannot be overemphasized. For instance, recent anthropogenic activities have enormously contributed to toxic substances in water bodies leading to unprecedented water pollution and impacting negatively on the ecosystem [1-3]. Hejazi et al. [4] have reported that the nature of this impact is enormous and worldwide; for example over one billion people lack reliable access to clean water and 2.3 billion people of the global population live in water-stressed areas, a number that will increase by $52 \%$ in 2025.

Removal of toxic chemical substances by adsorption using lowcost adsorbents is a method of choice in the water treatment process. This is due to the several techno-economic and

\footnotetext{
* Corresponding author.

E-mail address: helenalabie3@yahoo.com (A.H. Alabi).
}

environmental advantages associated with low-cost adsorbents when compared to other water treatment techniques; cheap, easy to obtain, process and use, available in abundance as waste or nuisance, good efficiency of adsorption and environmentally friendly [5-7]. Several low cost adsorbents such as biological materials [6-15], nanomaterials [16,17] and clays [5,18-24] have been investigated. However, most of these adsorbents suffer from limitations such as low efficiency of pollutant removal, technicality, low stability, bleeding, low mechanical strength, non-durability and/or poor re-usability, thus limiting their potential for applications. These have led to the search for more efficient and lower cost adsorbents.

In order to circumvent these limitations, modification techniques such as intercalation $[25,26]$ pillaring [5,27], organic surface treatment $[28,29]$, thermal activation [19,30], acid-alkaline treatment [5], and others have been used. However, the cost and efficiencies of these techniques are still major challenges.

Synergistic combinations of clays and biosorbents (both being low cost adsorbents) are beginning to receive attention [31] 
because these low cost sorbents are generally believed to increase the subsequent properties of the new adsorbents. This is achieved by combining individual characteristics of each composite to yield fewer final adsorbent limitations than the pure individual low cost adsorbents. Such synergistic combinations may lead to better sorbent properties such as high cation exchange capacity (CEC), reduce/eliminate bleeding, enhanced mechanical strength, pore size and consequently higher adsorption efficiency, better stability and durability, re-usability, sometimes larger surface area and even comparatively lower cost for water treatment. Some of these goals have been achieved by the calcination of kaolinite clays with pulverized Carica papaya seeds [31]. However, some clay properties suggest that not all such synergistic combinations may yield composites of better adsorption efficiencies. Hence, the aim of the study was to determine if calcined bentonite-biomass composites would yield higher adsorption efficiencies than the pristine bentonite clay. With the forgoing in mind, calcination of bentonite clay with pulverized $C$. papaya and pine cone were carried out in order to ascertain the above. The biomass-modified sorbents obtained were tested for the removal of $\mathrm{Pb}$ (II), $\mathrm{Cu}$ (II) and $\mathrm{Cd}(\mathrm{II})$ ions from aqueous solutions.

\section{Materials and method}

\subsection{Materials and pretreatments of the sorbents}

All reagents used for this study were analytical grade. $\mathrm{Pb}(\mathrm{II}), \mathrm{Cd}$ (II) and $\mathrm{Cu}(\mathrm{II})$ solutions were prepared from their chloride salts (Merck): lead (II) chloride ( $\left.\mathrm{PbCl}_{2}\right)$, cadmium (II) chloride $\left(\mathrm{CdCl}_{2}\right)$, copper (II) chloride $\left(\mathrm{CuCl}_{2}\right)$.

The $C$. papaya seeds were sourced from local markets in Ibadan, Nigeria. The pine cone seeds were obtained from the University of Ibadan, Botanical garden. The pretreatments and composites preparations were carried out by slight modification of the method of Unuabonah et al. [31]. All seeds were washed with tap water to remove dirt. These were sun-dried initially and later oven dried to remove moisture. The seeds were then pulverized to fineness using a steel blender sieved through a $230 \mu \mathrm{m}$ mesh size sieve and stored in an air-tight container.

Bentonite clay was obtained from the clay reserve of Federal Institute of Industrial Research Oshodi (FIIRO), Lagos, Nigeria. The clay was pretreated by suspension in deionized water for $24 \mathrm{~h}$ in order to remove sand and heavy non-clay materials, and the suspension was carefully decanted to obtain the bentonite clay only. The clay was further treated to remove organic matter by adding 30\% hydrogen peroxide solution and stirring the mixture until effervescence ceased. The mixture was decanted gently and washed five times to remove all traces of hydrogen peroxide and then oven dried at $105^{\circ} \mathrm{C}$ until constant weight. After cooling, the clay was ground, sieved through a $230 \mu \mathrm{m}$ mesh size sieve and stored in an air-tight container.

\subsection{Preparation of biomass-modified clay adsorbent}

Equal masses of purified bentonite and either of $C$. papaya or pine cone seeds ( $50 \mathrm{~g}$ each) were weighed into a $1 \mathrm{~L}$ beaker containing $300 \mathrm{~mL}$ of $0.1 \mathrm{M} \mathrm{NaOH}$ solution. The content was thoroughly stirred and heated in an oven at $105^{\circ} \mathrm{C}$ until dryness. These samples were placed in separate crucibles and calcined at $300^{\circ} \mathrm{C}$ for $6 \mathrm{~h}$. The resultant dark powdery material was washed several times to remove residual $\mathrm{NaOH}$ and then oven dried at $105^{\circ} \mathrm{C}$. The pure bentonite, the $C$. papaya and pine cone seeds modified bentonite clay was referred to as BEN, CPB and PCB, respectively. Schematics of the modification processes are shown in Supporting material (SM) Fig. 1.

\subsection{Characterization of the sorbents}

The samples diffractogram were obtained with a Bruker phaser diffractometer system using the randomly oriented mounts procedure and scanning from 5 to $70^{\circ} \theta$. pH of the samples were determined in deionized water (sample: water ratio of 1:2). The $\mathrm{pH}$ at point of zero charge $\left(\mathrm{pH}_{\mathrm{PZC}}\right)$ was determined (SM 1) by the $\mathrm{pH}$ drift method [12]. Cation exchange capacity (CEC) of the
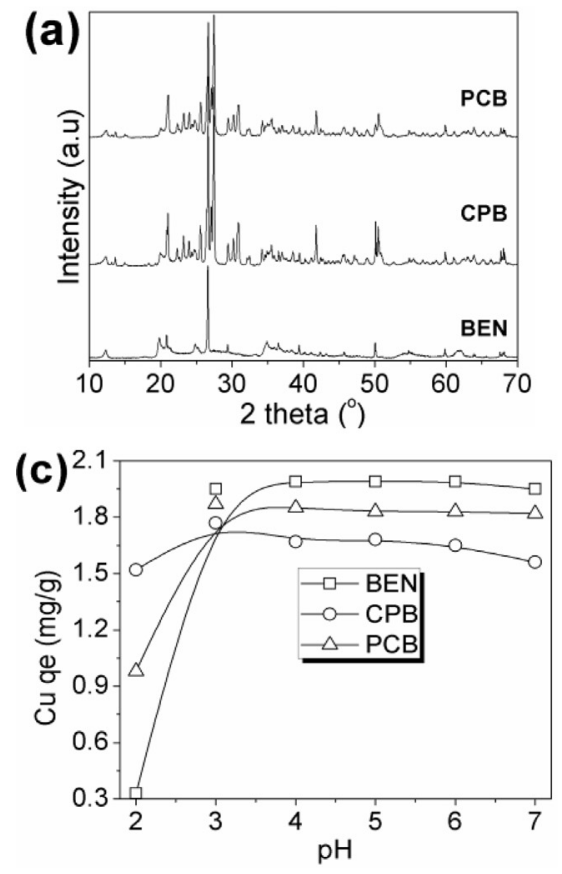
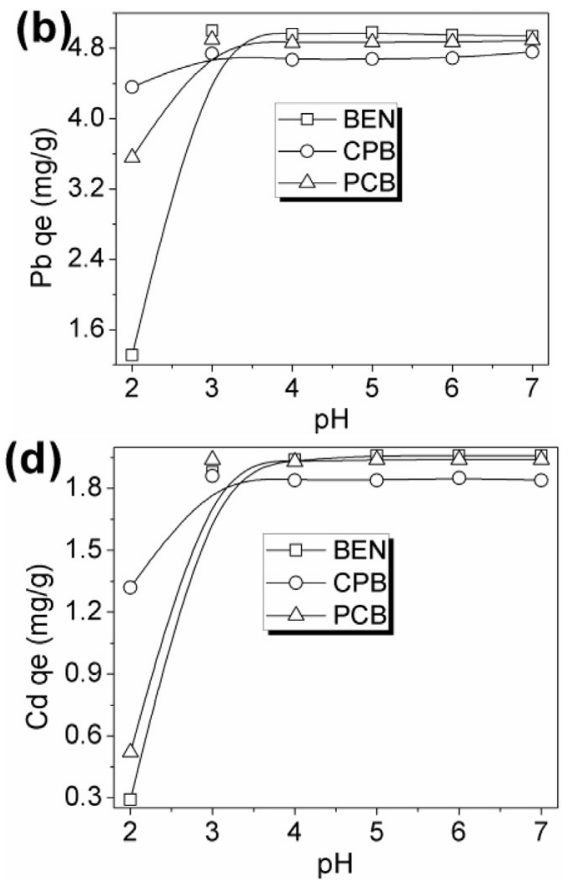

Fig. 1. (a) X-ray diffraction patterns of $\mathrm{BEN}, \mathrm{CPB}$ and $\mathrm{PCB}$; effect of $\mathrm{pH}$ on the adsorption of (b) $\mathrm{Pb}(\mathrm{II})$, (c) $\mathrm{Cu}(\mathrm{II}) \mathrm{and}(\mathrm{c}) \mathrm{Cd}(\mathrm{II})$ ions. 
adsorbents was determined using the sodium saturation method by adding $25 \mathrm{~mL}$ of $1 \mathrm{M}$ sodium acetate solution to $1 \mathrm{~g}$ of the adsorbent which resulted in the exchange of matrix cations with the added sodium ions. The samples were then washed with 15 and $10 \mathrm{~mL}$ portions of isopropyl alcohol to remove excess sodium acetate. The exchanged sodium ions on the adsorbents were subsequently washed with 15 and $10 \mathrm{~mL}$ portions of $1 \mathrm{M}$ ammonium acetate solutions to displace the adsorbed sodium with ammonium. The concentrations of displaced sodium were determined. Surface area was determined using Micromeritics ASAP $2020 \mathrm{M}+\mathrm{C}$ accelerated surface area analyzer (Micromeritics Instrument Corporation, USA).

\subsection{Micro-pollutants adsorption experiments}

Adsorption experiments were carried out by adding $20 \mathrm{~mL}$ solution of specified concentration of the micro-pollutants ( $\mathrm{Pb}(\mathrm{II})$, $\mathrm{Cu}(\mathrm{II})$ and $\mathrm{Cd}(\mathrm{II}))$ into vials containing $100 \mathrm{mg}$ of the adsorbent. The adsorbent and micro-pollutant mixtures were then equilibrated by shaking at $100 \mathrm{rpm}$ in a temperature $\left(25^{\circ} \mathrm{C}\right)$ controlled shaker until equilibrium; where necessary during the experiments, the $\mathrm{pH}$ of the working solutions were adjusted by adding drops of either $\mathrm{HCl}$ or $\mathrm{NaOH}$. Effect of $\mathrm{pH}$ on adsorption of the micro-pollutants was carried out by varying $\mathrm{pH}$ from 2 to 7 using $50 \mathrm{mg} / \mathrm{L}$ of micropollutants and equilibrating for $1440 \mathrm{~min}$, effect of time was investigated by using $50 \mathrm{mg} / \mathrm{L}$ of the micropollutant and time varied from 15 to $1440 \mathrm{~min}$, equilibrium experiments were studied at temperatures of 25 and $50^{\circ} \mathrm{C}$, while varying the concentrations from 0 to $70 \mathrm{mg} / \mathrm{L}$ at solution $\mathrm{pH}$ of $5.0 \pm 0.2$ and equilibrating for $1440 \mathrm{~min}$. At equilibrium, the vials were centrifuged at $3000 \mathrm{rpm}$ for $10 \mathrm{~min}$. and the concentrations of micro-pollutants left in solution were determined using the Varian AA240FS Atomic Absorption Spectrometer (AAS) with air-acetylene flame on absorbance mode. The experiments were conducted in duplicate and the mean of the values were used for computation.

\subsection{Data treatment}

The amounts of metal ions adsorbed were calculated from the initial $\left(C_{\mathrm{o}}\right)$ and final $\left(C_{\mathrm{e}}\right)$ concentrations in solutions after equilibration using Eq. (1):

$q_{\mathrm{e}}=\frac{\left(C_{0}-C_{\mathrm{e}}\right) V}{M}$

where $q_{\mathrm{e}}, V$ and $M$ are the amount of metal ions adsorbed $(\mathrm{mg} / \mathrm{g})$, volume of the solution $(\mathrm{mL})$ and mass $(\mathrm{g})$ of adsorbent used, respectively.

The linear forms of Lagergren [32] Pseudo-first order (PFO), Pseudo-second order (PSO) and the Weber and Morris [33] Intraparticle diffusion (IPD) models were used to describe the adsorption data; as well as the Langmuir [34] and Freundlich [35] adsorption isotherm models (SM 2).

\section{Results and discussion}

\subsection{Characterization Results}

The powder XRD diffraction patterns (Fig. 1a) of BEN and the modified bentonite clays ( $\mathrm{PB}$ and $\mathrm{PCB}$ ) revealed that the calcination of the clay did not lead to any observable change in the position of the diffraction peaks of all the adsorbents from 10 to $70^{\circ} 2 \theta(001)$. The diffraction patterns of the modified clays were typically the same as those of the unmodified clays. This similarity between the diffractograms is an indication that biomassmodification of clays does not promote any structural modification in the basic d-spacing on the lattice structure of the pure clay mineral, except the impregnation of the calcined biomaterials on the clay surface. Similar result has been reported by Unuabonah et al. [31] for the biomass-modification of Kaolinite clay.

The XRD results were supported by other physicochemical parameters e.g. the specific surface area data showed that calcination of clays in the presence of biomass reduced the surface area of the clay (SM Table 1 ). The surface area of the clay reduced from $64 \mathrm{~m}^{2} / \mathrm{g}$ to $\approx 15$ and $14 \mathrm{~m}^{2} / \mathrm{g}$ in the CPB and PCB adsorbents, respectively; the CEC reduced from 101.2 to 62.9 and $97.7 \mathrm{meq} /$ $100 \mathrm{~g}$ while the pHpzc also reduced from 8.1 to 7.8 and 7.2 for CPB and $\mathrm{PCB}$, respectively. The reductions in $\mathrm{CEC}$ and $\mathrm{pHpzc}$ may be attributed to the slight chemical deformation of bentonite (dehydroxylation) caused by heating which does not affect the crystal structure [36].

\subsection{Effect of $\mathrm{pH}$ on $\mathrm{Pb}(\mathrm{II}), \mathrm{Cu}(\mathrm{II})$ and $\mathrm{Cd}(\mathrm{II})$ adsorption}

Fig. $1 \mathrm{~b}$ and $\mathrm{c}$ shows the results of the effect of $\mathrm{pH}$ on the adsorption of $\mathrm{Pb}(\mathrm{II}), \mathrm{Cu}(\mathrm{II})$ and $\mathrm{Cd}(\mathrm{II})$ on BEN, CPB and $\mathrm{PCB}$ adsorbents. It was observed that the adsorption was $\mathrm{pH}$ dependent and increased with increase in $\mathrm{pH}$ until $\mathrm{pH} 3$ where optimum adsorption were observed for all adsorbents. Similar adsorption trend has been reported in literature [12]. The quantities of metals ions adsorbed onto the clay adsorption sites were low at low $\mathrm{pH}$ values (less than 3 ), but as solution $\mathrm{pH}$ increased the quantities increased rapidly until optimum $\mathrm{pH}$ where the highest adsorption were recorded. These results showed that pure and modified bentonite clays can be used for adsorption of metals in solutions having $\mathrm{pH}$ between 3 and 7. This is a wide $\mathrm{pH}$ range of adsorption unlike those of most adsorbents in literature with narrow optimum $\mathrm{pH}$ range of adsorption; hence, these adsorbents may be applied for pollutants adsorption from a wide range of aqueous acidic solutions. This adsorption trend has been attributed to the nature and ionization of adsorption surfaces and metals ions in

Table 1

Calculated kinetics model parameters.

\begin{tabular}{|c|c|c|c|c|c|c|c|c|c|c|}
\hline & & \multicolumn{3}{|l|}{ BEN } & \multicolumn{3}{|l|}{$\mathrm{CPB}$} & \multicolumn{3}{|l|}{ РCB } \\
\hline & & $\mathrm{Pb}(\mathrm{II})$ & $\mathrm{Cu}(\mathrm{II})$ & $\mathrm{Cd}(\mathrm{II})$ & $\mathrm{Pb}(\mathrm{II})$ & $\mathrm{Cu}(\mathrm{II})$ & $\mathrm{Cd}(\mathrm{II})$ & $\mathrm{Pb}(\mathrm{II})$ & $\mathrm{Cu}(\mathrm{II})$ & $\mathrm{Cd}(\mathrm{II})$ \\
\hline \multirow[t]{3}{*}{ PFO } & $q_{\mathrm{e}}\left(\mathrm{mg} \mathrm{g}^{-1}\right)$ & 8.22 & 1.90 & 2.18 & 4.01 & 2.29 & 2.22 & 7.76 & 2.32 & 2.37 \\
\hline & $K_{1} \times 10^{-4}\left(\mathrm{~min}^{-1}\right)$ & 0.00 & 0.00 & 0.00 & 0.00 & 0.00 & 0.00 & 0.00 & 0.00 & 0.00 \\
\hline & $r^{2}$ & 0.686 & 0.916 & 0.694 & 0.616 & 0.567 & 0.547 & 0.432 & 0.570 & 0.481 \\
\hline \multirow[t]{3}{*}{ PSO } & $q_{\mathrm{e}}\left(\mathrm{mg} \mathrm{g}^{-1}\right)$ & 0.49 & 0.10 & 0.15 & 0.43 & 0.19 & 0.18 & 0.49 & 0.19 & 0.19 \\
\hline & $K_{2}\left(\mathrm{~g} \mathrm{mg}^{-1} \min ^{-1}\right)$ & 0.90 & 0.27 & 1.11 & 0.16 & 0.61 & 0.49 & 0.97 & 0.93 & 1.47 \\
\hline & $r^{2}$ & 1.000 & 0.996 & 0.999 & 0.999 & 0.999 & 0.999 & 1.000 & 1.000 & 1.000 \\
\hline \multirow[t]{3}{*}{ IPD } & $C\left(\mathrm{mg} \mathrm{g}^{-1}\right)$ & 0.47 & 0.07 & 0.14 & 0.32 & 0.16 & 0.14 & 0.46 & 0.16 & 0.17 \\
\hline & $K_{\mathrm{id}}$ & 0.007 & 0.001 & 0.001 & 0.003 & 0.001 & 0.001 & 0.001 & 0.001 & 0.001 \\
\hline & $r^{2}$ & 0.877 & 0.945 & 0.887 & 0.787 & 0.781 & 0.743 & 0.603 & 0.781 & 0.69 \\
\hline \multicolumn{2}{|c|}{ Experimental $q_{\mathrm{e}}\left(\mu \mathrm{gg}^{-1}\right)$} & 0.49 & 0.10 & 0.15 & 0.43 & 0.19 & 0.18 & 0.49 & 0.19 & 0.19 \\
\hline
\end{tabular}



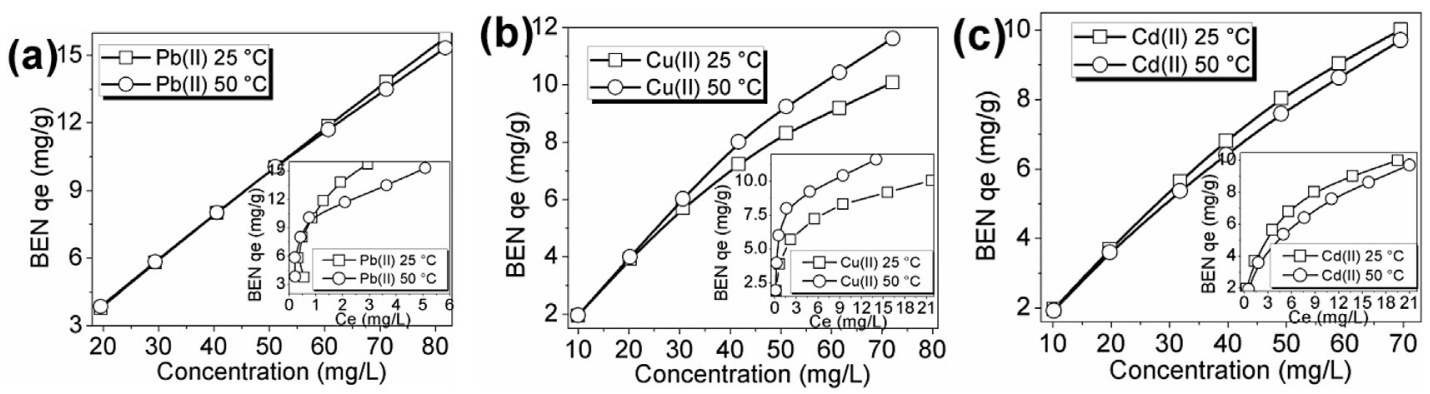

Fig. 2. Pure bentonite adsorption trend with increase in concentration for (a) $\mathrm{Pb}(\mathrm{II}),(\mathrm{b}) \mathrm{Cu}(\mathrm{II})$ and (c) $\mathrm{Cd}(\mathrm{II})$ (Insert: isotherm plot of $q_{\mathrm{e}} \mathrm{vs} C_{\mathrm{e}}$ ).

solution at various $\mathrm{pH}$ values [12]. At low $\mathrm{pH}$ values (around 2) there is stiff competition between the $\mathrm{H}^{+}$and positively charged metal ions for the negatively charged adsorption sites causing protonation of negatively charged adsorption sites, i.e. the sites become uncharged. This means that the metal ions may not have the opportunity of being adsorbed or are displaced from the adsorption sites by protons, both cases resulting in low surface adsorption. However, as solution $\mathrm{pH}$ increases, this competition reduces due to reduction in the concentration of $\mathrm{H}^{+}$in solution; resulting in increased adsorption. This increase in adsorption occurs steadily with $\mathrm{pH}$ until optimum $\mathrm{pH}$ when further adsorption is not possible and the horizontal part of the curve in Fig. 1 is observed.

The slight changes in pHpzc $(<1.0)$ from BEN to CPB and $\mathrm{PCB}$ notwithstanding (SM Table 1), it was observed that adsorption of these cations was significantly below the $\mathrm{pHpzc}$ value. It has been suggested [31,37] that the modification process resulted in the formation of surface amide II groups (SM Fig. 2) whose delocalized $\pi$-electrons increased the electrostatic interactions between the adsorbents' surfaces and metal ions. The delocalized $\pi$-electrons were activated via calcination of the biomass materials. Hence, the cation adsorption may be attributed to electron donor-acceptor complexes in lewis bases of functional groups such as pyrones or chromenes [37].

\subsection{Effect of time on $\mathrm{Pb}(\mathrm{II}), \mathrm{Cu}(\mathrm{II})$ and $\mathrm{Cd}(\mathrm{II})$ adsorption}

The effect of time on the adsorption of $\mathrm{Pb}$ (II), $\mathrm{Cu}$ (II) and $\mathrm{Cd}(\mathrm{II})$ ions on BEN, CPB and PCB adsorbents (SM Fig. 3) suggested that the times for attainment of equilibrium for each metal differ from one sorbent to the other. For $\mathrm{Pb}(\mathrm{II})$ adsorption, equilibrium was attained in $400 \mathrm{~min}$ on BEN and PCB adsorbents, while the time was longer on $\mathrm{CPB}$ adsorbents. $\mathrm{Cu}$ (II) adsorption on BEN was very slow $(1400 \mathrm{~min})$ but it was faster in the modified adsorbents (400 min). However, Cd(II) adsorption showed similar trend for BEN, CPB and PCB adsorbents, and equilibrium was attained in approximately $500 \mathrm{~min}$.

The effect of time data for the adsorption of $\mathrm{Pb}(\mathrm{II}), \mathrm{Cu}(\mathrm{II})$ and $\mathrm{Cd}$ (II) ions on BEN, CPB and PCB adsorbents were fitted to the PFO, PSO and IPD kinetics models. The estimated kinetics model parameters are shown in Table 1. It was observed that the PSO was more appropriate in describing the data than the PFO; comparison of the calculated PFO and PSO models parameters-adsorption capacity $\left(q_{\mathrm{e}}\right)$ and the magnitude of the correlation coefficient $\left(r^{2}\right)$ values, showed that the PSO $q_{\mathrm{e}}$ values were closer to the experimental values and the $r^{2}$ values were closer to unity ( $\geq 0.996)$. The $q_{\mathrm{e}}$ values for the PFO showed very high overestimations of the adsorption capacities of the adsorbents and the $r^{2}$ values were not correlated. These results indicated that the
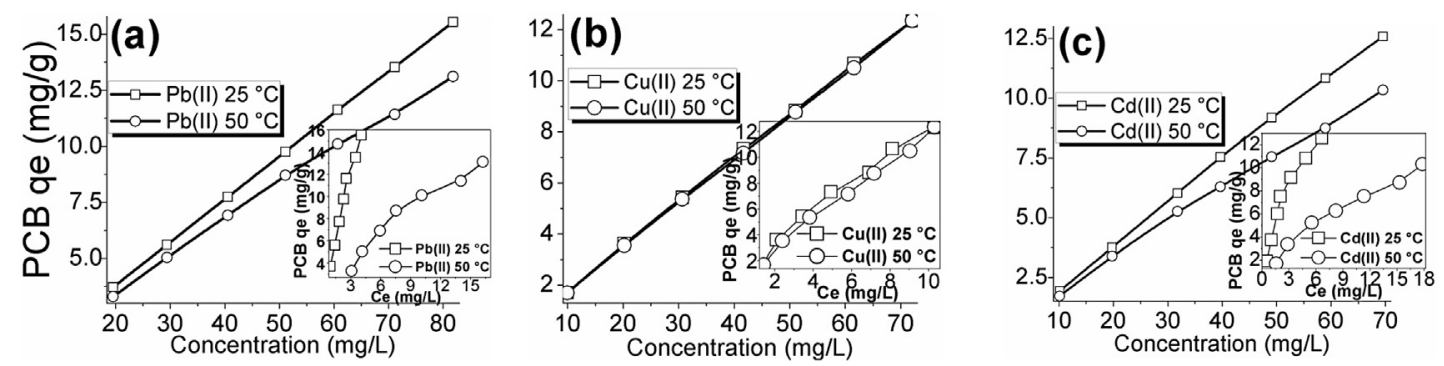

Fig. 3. $\mathrm{PCB}$ adsorption trend with increase in concentration for (a) $\mathrm{Pb}(\mathrm{II}),(\mathrm{b}) \mathrm{Cu}(\mathrm{II})$ and (c) $\mathrm{Cd}(\mathrm{II})$ (Insert: isotherm plot of $q_{\mathrm{e}}$ vs $C_{\mathrm{e}}$ ).
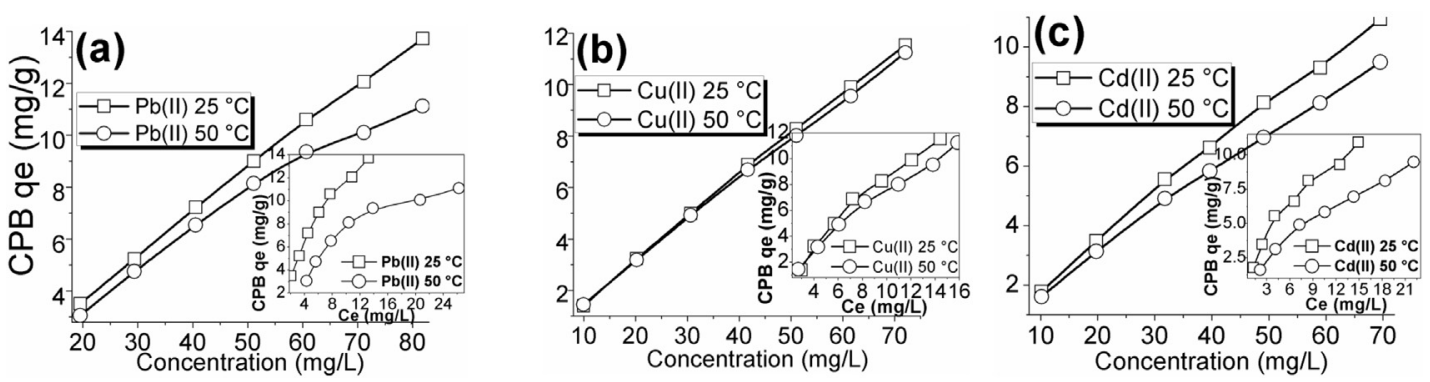

Fig. 4. $\mathrm{CPB}$ adsorption trend with increase in concentration for (a) $\mathrm{Pb}(\mathrm{II})$, (b) $\mathrm{Cu}(\mathrm{II})$ and (c) $\mathrm{Cd}(\mathrm{II})$ (Insert: isotherm plot of $q_{\mathrm{e}}$ vs $C_{\mathrm{e}}$ ). 

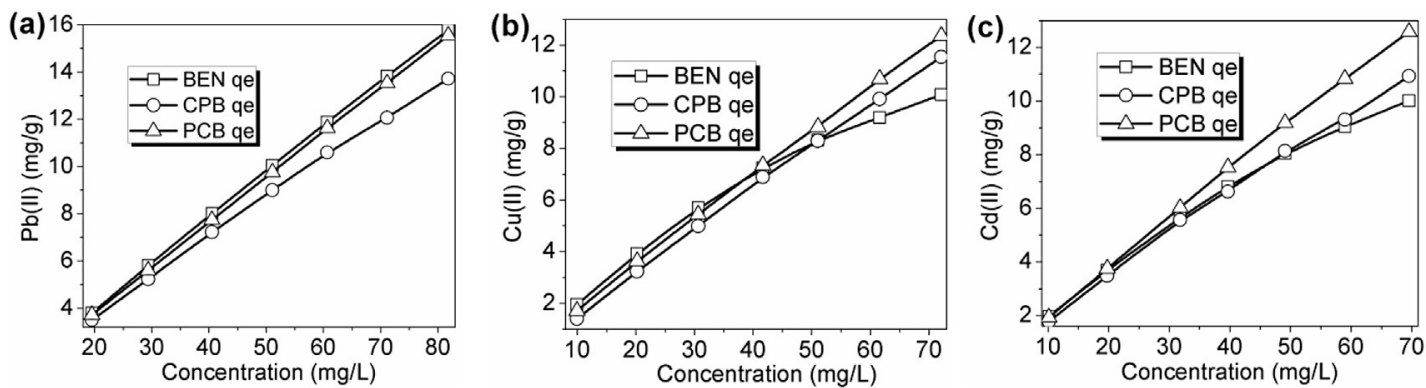

Fig. 5. Comparison of the adsorption trends of BEN, CPB and PCB with increase in concentration at $25^{\circ} \mathrm{C}$ for (a) $\mathrm{Pb}(\mathrm{II})$, (b) $\mathrm{Cu}(\mathrm{II})$ and (c) $\mathrm{Cd}(\mathrm{II})$.

mechanism of removal of these metal species from aqueous solutions onto the adsorbents was ion exchange [12,14]. The values of IPD model parameter, $C(\mathrm{mg} / \mathrm{g})$ and $r^{2}$ values also showed that the data could be explained by this model. The magnitude of the parameter $C$ indicated the thickness of the adsorbed species on the adsorbent surface; if the $C$ value equals the experimental $q_{\mathrm{e}}$ values, then surface adsorption accounted for the bulk of the pollutants removal from solution [33]. In this study, it was observed that the bulk of the adsorption occurred on the surfaces of the adsorbents because the $C(\mathrm{mg} / \mathrm{g})$ values were approximately equal to the experimental $q_{\mathrm{e}}(\mathrm{mg} / \mathrm{g})$ values (Table 1$)$.

\subsection{Equilibrium experiments and effect of temperature}

Figs. 2-4 showed equilibrium adsorption trend as concentration increased. It was observed that increasing the concentration of the metal in solution resulted in higher sorption of the metal. This trend was attributed to the fact that when the transport of metals between the sorbent's external surface film and internal pores are equal, the trans-boundary movement of metals will not be significantly permissible; however, increasing concentration will re-initiate the trans-boundary movement and hence, the process will be concentration dependent. Similar findings have been reported in literature for similar and other pollutants adsorption $[1,38,39]$. The Figures also showed that increase in temperature did not lead to any significant increase in adsorption except for $\mathrm{Cu}(\mathrm{II})$ on the BEN clay.

The adsorption isotherm curves for all adsorbates obtained by plotting the $q_{\mathrm{e}} \mathrm{vs} C_{\mathrm{e}}$ data are shown in the inserts of Figs. 2-4. It was observed that the isotherm curves at both temperatures (298 and $323 \mathrm{~K}$ ) fitted the L-type isotherm [40], and this was indicative of adsorbates adsorbed flat on the surface or sometimes, of vertically oriented adsorbates with particularly strong intermolecular attraction.

Comparing the adsorption of each metal by the BEN, CPB and PCB adsorbents-Fig. 5, it was observed that pine cone modification exhibited better adsorption capacity than the $C$. papaya modification and BEN for $\mathrm{Cd}(\mathrm{II})$ and $\mathrm{Cu}(\mathrm{II})$ adsorption while the adsorption of $\mathrm{Pb}(\mathrm{II})$ on all three adsorbents (Fig. 5b and c) showed that modification did not enhance the capacity of BEN for these metals, instead a reduction was observed. It was also observed that increase in solution temperature resulted mainly in decrease in the uptake of the metal species from aqueous solution (Figs. 2-4).

The adsorption data at $298 \mathrm{~K}$ were fitted to the linear forms of the Langmuir and Freundlich adsorption isotherms (Table 2). It was observed that all data fitted the Freundlich adsorption isotherm model $\left(r^{2} \geq 0.70\right)$ with the exception of $\mathrm{Cu}$ (II) and $\mathrm{Cd}(\mathrm{II})$ adsorption on BEN which could be explained by both models. The Langmuir isotherm model assumes that the adsorption occur on sites having equal affinity for the pollutants and forms an adsorbate monolayer on the adsorbent surfaces at equilibrium. One reason Langmuir model could not be used to explain the data may not be unconnected to the fact that the adsorbents are composites having different adsorption sites being contributed by both the pure BEN and the calcined biosorbent material. However, the fitting of these results to the Freundlich isotherm model indicated that the adsorption occurred on heterogeneous surfaces of unequal energy with possible formation of adsorbate multilayer on the adsorbent surfaces at equilibrium. For the adsorption of $\mathrm{Cu}$ (II) and Cd(II) onto BEN which showed exceptions to the Freundlich isotherm model these were attributed to adsorption on different sites with similar energies. Such adsorption can easily be explained using the Langmuir isotherm model (Table 2). Also, combination of several Langmuir adsorption isotherm models occurring simultaneously have been shown to give a good approximation to the Freundlich type isotherm model [41]; hence, the data of $\mathrm{Cu}$ (II) and $\mathrm{Cd}(\mathrm{II})$ adsorption on BEN could be explained by both models. $\mathrm{Pb}$ (II) adsorption on BEN did not fit the Langmuir isotherm model, and this indicated $\mathrm{Pb}$ (II) adsorption occurred on heterogeneous surfaces of unequal energy.

In general, these biomass modifications of BEN did not enhance adsorption efficiency for the aqueous removal of $\mathrm{Pb}$ (II) but did for $\mathrm{Cd}(\mathrm{II})$ and $\mathrm{Cu}(\mathrm{II})$ ions. This may be explained thus: bentonite is a 2:1 expansive clay mineral and there is the likelihood that the modification blocked some pores on BEN while creating almost equal amount of new adsorption sites; secondly, $\mathrm{Pb}$ (II) [and to a lesser extent $\mathrm{Cu}(\mathrm{II})]$ form strong inner-sphere complexes with oxides of $\mathrm{Fe}, \mathrm{Al}$ and $\mathrm{Mn}$ in clay minerals [42,43]; hence, blockage of the clay pores (reduction of access to oxides) may lead to reduced inner-sphere complex formation and consequently the reduced $\mathrm{Pb}$

Table 2

Langmuir and Freundlich adsorption isotherm model parameters for $\mathrm{Pb}(\mathrm{II}), \mathrm{Cu}(\mathrm{II})$, and $\mathrm{Cd}(\mathrm{II})$ adsorptions.

\begin{tabular}{|c|c|c|c|c|c|c|c|c|c|c|}
\hline \multirow[t]{2}{*}{ Model } & \multirow[t]{2}{*}{ Parameter } & \multicolumn{3}{|l|}{$\mathrm{Pb}(\mathrm{II})$} & \multicolumn{3}{|l|}{$\mathrm{Cu}(\mathrm{II})$} & \multicolumn{3}{|l|}{$\mathrm{Cd}(\mathrm{II})$} \\
\hline & & BEN & $\mathrm{CPB}$ & PCB & BEN & $\mathrm{CPB}$ & РCB & BEN & $\mathrm{CPB}$ & РCB \\
\hline \multirow[t]{3}{*}{ Langmuir } & $Q_{0}(\mathrm{mg} / \mathrm{g})$ & 19.61 & 17.76 & 23.2 & 10.16 & 32.79 & 20 & 10.47 & 13.61 & 16.45 \\
\hline & $\beta$ & 1.15 & 0.19 & 0.35 & 0.84 & 0.03 & 0.13 & 0.52 & 0.19 & 0.41 \\
\hline & $r^{2}$ & 0.69 & 0.75 & 0.42 & 0.99 & 0.07 & 0.44 & 0.98 & 0.81 & 0.79 \\
\hline \multirow[t]{3}{*}{ Freundlich } & $n$ & 0.54 & 0.73 & 0.99 & 0.32 & 1.24 & 0.92 & 0.39 & 0.70 & 0.73 \\
\hline & $K_{\mathrm{f}}$ & 9.36 & 2.26 & 4.10 & 4.02 & 2.01 & 1.58 & 3.30 & 1.77 & 3.69 \\
\hline & $r^{2}$ & 0.70 & 0.98 & 0.98 & 0.97 & 0.94 & 0.97 & 0.99 & 0.97 & 0.96 \\
\hline \multicolumn{2}{|c|}{ Experimental $q_{\mathrm{e}}(\mathrm{mg} / \mathrm{g})$} & 15.78 & 13.72 & 15.55 & 10.08 & 11.54 & 12.36 & 10.01 & 10.93 & 12.58 \\
\hline
\end{tabular}


(II) adsorption. However, since $\mathrm{Cd}(\mathrm{II})$ and $\mathrm{Cu}(\mathrm{II})$ ions are retained by weaker exchange reactions in clay minerals [42], the new surfaces introduced by the modifications became adsorption sites for both cations, hence the slightly improved adsorption.

\section{Conclusion}

Synergistic combination of low-cost adsorbents is a promising technology for enhanced removal of aqueous pollutants from solution. However, not all composites of clay and biomass enhance aqueous metal removal efficiency as revealed in this study. The present study showed that modification of bentonite clay with $C$. papaya seeds or pine cone using the calcination method is possible but the process did not enhance the adsorption capacity of bentonite clay for the aqueous removal of $\mathrm{Pb}(\mathrm{II})$ but did for $\mathrm{Cd}(\mathrm{II})$ and $\mathrm{Cu}(\mathrm{II})$ ions. However, other parameters such as removal of adsorbent bleeding, easier separation of bentonite clay (high swelling clay) from aqueous solution and better mechanical strength were achieved. Another striking observation was that the adsorption efficiencies of these sorbents were stable over a wide range of $\mathrm{pH}(\mathrm{pH} 3-7)$. Hence the modification process was successful and the modified adsorbents can reduce adsorbent bleeding, enhance separation of bentonite from aqueous solution, improve mechanical strength, as well as produce adsorbents that may be applied for pollutants removal from a wide range of aqueous acidic solutions.

\section{Acknowledgements}

We acknowledge the supports of Alexander von Humboldt Stiftung Foundation Research group linkage Program and the Institute of Soil Science and Soil Conservation, Justus Liebig University, Giessen, Germany where part of the study was done.

\section{Appendix A. Supplementary data}

Further information on the: SM Fig. 1-Schematic of bentonite modifications with Carica Papaya and Pine cone; SM 1: pH at point of zero charge $\left(\mathrm{pH}_{\mathrm{PzC}}\right)$ determination; SM Table 1-Physicochemical parameters of the pure and modified bentonite clays; SM 2: Data Treatment; SM 3: FTIR Spectra; SM Fig. 2-Infra red spectra of BEN, CPB and PCB adsorbents; SM Fig. 3-Effect of time on the adsorption of (a) $\mathrm{Pb}(\mathrm{II})$, (b) $\mathrm{Cu}(\mathrm{II})$ and (c) $\mathrm{Cd}(\mathrm{II})$ ions on BEN, CPB and PCB adsorbents.

Supplementary data associated with this article can be found, in the online version, at http://dx.doi.org/10.1016/j.jece.2016.01.044.

\section{References}

[1] B.I. Olu-Owolabi, P.N. Diagboya, K.O. Adebowale, Evaluation of pyrene sorption-desorption on tropical soils, J. Environ. Manage. 137 (2014) 1-9.

[2] C.P. Okoli, G.O. Adewuyi, O. Zhang, P.N. Diagboya, Q. Guo, Mechanism of dialkyl phthalates removal from aqueous solution using $\gamma$-cyclodextrin and starch based polyurethane polymer adsorbents, Carbohydr. Polym. 114 (2014) 440449.

[3] B.I. Olu-Owolabi, P.N. Diagboya, K.O. Adebowale, Sorption and desorption of fluorene on five tropical soils from different climes, Geoderma 239-240 (2015) 179-185.

[4] S.R. Hejazi, J. Yadolahi, M. Shahverdi, J. Malakootikhah, Identifying nanotechnology-based entrepreneurial opportunities in line with waterrelated problems, Middle East J. Sci. Res. 8 (2011) 337-348.

[5] K.G. Bhattacharyya, S.S. Gupta, Adsorption of a few heavy metals on natura and modified kaolinite and montmorillonite: a review, Adv. Colloid Interface Sci. 140 (2008) 114-131.

[6] M.A. Olivella, P. Jove, A. Oliveras, The use of cork waste as a biosorbent for persistent organic pollutants-study of adsorption/desorption of polycyclic aromatic hydrocarbons, J. Environ. Sci. Health A Tox. Hazard. Subst. Environ. Eng. 46 (2011) 824-832.

[7] B.I. Olu-Owolabi, P.N. Diagboya, W.C. Ebaddan, Mechanism of Pb(II) removal from aqueous solution using a nonliving moss biomass, Chem. Eng. J. 195-196 (195) (2012) 270--.
[8] S.W. Al Rmalli, A.A. Dahmani, M.M. Abuein, A.A. Gleza, Biosorption of mercury from aqueous solutions by powdered leaves of castor tree (Ricinus communis L.), J. Hazard. Mater. 152 (2008) 955-959.

[9] B. Chen, M. Yuan, H. Liu, Removal of polycyclic aromatic hydrocarbons from aqueous solution using plant residue materials as a biosorbent, J. Hazard. Mater. 188 (2011) 436-442.

[10] S.M. De Oliveira Brito, H.M. Andrade, L.F. Soares, R.P. De Azevedo, Brazil nut shells as a new biosorbent to remove methylene blue and indigo carmine from aqueous solutions, J. Hazard. Mater. 174 (2010) 84-92.

[11] H.K. Hansen, F. Arancibia, C. Gutierrez, Adsorption of copper onto agriculture waste materials, J. Hazard. Mater. 180 (2010) 442-448.

[12] A.E. Ofomaja, E.B. Naidoo, S.J. Modise, Removal of copper(II) from aqueous solution by pine and base modified pine cone powder as biosorbent, J. Hazard. Mater. 168 (2009) 909-917.

[13] P. Saha, Assessment on the removal of methylene blue dye using tamarind fruit shell as biosorbent, Water Air Soil Pollut. 213 (2010) 287-299.

[14] A. Seker, T. Shahwan, A.E. Eroglu, S. Yilmaz, Z. Demirel, M.C. Dalay, Equilibrium thermodynamic and kinetic studies for the biosorption of aqueous lead(II) cadmium(II) and nickel(II) ions on Spirulina platensis, J. Hazard. Mater. 154 (2008) 973-980.

[15] R. Vimala, N. Das, Biosorption of cadmium (II) and lead (II) from aqueous solutions using mushrooms: a comparative study, J. Hazard. Mater. 168 (2009) 376-382.

[16] P.N. Diagboya, B.I. Olu-Owolabi, K.O. Adebowale, Microscale scavenging of pentachlorophenol in water using amine and tripolyphosphate-grafted SBA15 silica: batch and modeling studies, J. Environ. Manage. 146 (2014) 42-49.

[17] P.N. Diagboya, B.I. Olu-Owolabi, D. Zhou, B.-H. Han, Graphene oxidetripolyphosphate hybrid material: a potent sorbent for cationic dyes, Carbon 79 (2014) 174-182.

[18] I. Ali, M. Asim, T.A. Khan, Low cost adsorbents for the removal of organic pollutants from wastewater, J. Environ. Manage. 113 (2012) 170-183.

[19] I. Chaari, E. Fakhfakh, S. Chakroun, J. Bouzid, N. Boujelben, M. Feki, F. Rocha, F Jamoussi, Lead removal from aqueous solutions by a Tunisian smectitic clay, J. Hazard. Mater. 156 (2008) 545-551.

[20] L. Chen, S. Lu, Sorption and desorption of radiocobalt on montmorilloniteeffects of pH, ionic strength and fulvic acid, Appl. Radiat. Isot. 66 (2008) 288294.

[21] E.F. Covelo, N. Alvarez, M.L. Andrade, F.A. Vega, P. Marcet, Zn adsorption by different fractions of Galician soils, J. Colloid Interf. Sci. 280 (2004) 343-349.

[22] J. Hizal, R. Apak, Modeling of cadmium(II) adsorption on kaolinite-based clays in the absence and presence of humic acid, Appl. Clay Sci. 32 (2006) 232-244.

[23] S.H. Lin, R.C. Hsiao, R.S. Juang, Removal of soluble organics from water by a hybrid process of clay adsorption and membrane filtration, J. Hazard. Mater. 135 (2006) 134-140.

[24] J.C. Miranda-Trevino, C.A. Coles, Kaolinite properties, structure and influence of metal retention on pH, Appl. Clay Sci. 23 (2003) 133-139.

[25] T.A. Elbokl, C. Detellier, Aluminosilicate nanohybrid materials. Intercalation of polystyrene in kaolinite, J. Phys. Chem. Solids 67 (2006) 950-955.

[26] B. Zhang, Y. Li, X. Pan, X. Jia, X. Wang, Intercalation of acrylic acid and sodium acrylate into kaolinite and their in situ polymerization, J. Phys. Chem. Solids 68 (2007) 135-142.

[27] M.F. Hou, C.X. Ma, W.D. Zhang, X.Y. Tang, Y.N. Fan, H.F. Wan, Removal of rhodamine B using iron-pillared bentonite, J. Hazard. Mater. 186 (2011) 11181123.

[28] B. Sarkar, Y. Xi, M. Megharaj, G.S. Krishnamurti, R. Naidu, Synthesis and characterisation of novel organopalygorskites for removal of p-nitrophenol from aqueous solution: isothermal studies, J. Colloid Interface Sci. 350 (2010) 295-304.

[29] B. Sarkar, Y. Xi, M. Megharaj, G.S. Krishnamurti, D. Rajarathnam, R. Naidu, Remediation of hexavalent chromium through adsorption by bentonite based Arquad(R) 2HT-75 organoclays, J. Hazard. Mater. 183 (2010) 87-97.

[30] A.R. Kul, H. Koyuncu, Adsorption of $\mathrm{Pb}$ (II) ions from aqueous solution by native and activated bentonite: kinetic, equilibrium and thermodynamic study, J. Hazard. Mater. 179 (2010) 332-339.

[31] E.I. Unuabonah, C. Gunter, J. Weber, S. Lubahn, A. Taubert, Hybrid clay a new highly efficient adsorbent for water treatment, ACS Sustain. Chem. Eng. 1 (2013) 966-973.

[32] S. Lagergren, Zur theorie der sogenannten adsorption gelöster stoffe. Kungliga Svenska Vetenskapsakademiens, Handlingar 24 (1898) 1-39.

[33] W.J. Weber, J.C. Morris, Kinetics of adsorption on carbon from solutions. Journal of Sanitary Engineering Division, Am. Soc. Civil Eng. 89 (1963) 31-60.

[34] I. Langmuir, The constitution and fundamental properties of solids and liquids, J Am. Chem. Soc. 38 (1916) 2221-2295.

[35] H.M.F. Freundlich, Über die adsorption in lösungen, Zeitschrift für Physikalische Chemie 57A (1906) 385-470.

[36] Y. Sarikaya, M. Onal, B. Baran, T. Alendaroglu, The effect of thermal treatment on some of the physicochemical properties of a bentonite, Clays Clay Miner. 48 (2000) 557-562.

[37] J. Rivera-Utrilla, M. Sanchez-Polo, Adsorption of Cr(III) on ozonised activated carbon. Importance of $C \pi$-cation interactions, Water Res. 37 (2003) 3335 3340.

[38] C. An, G. Huang, H. Yu, J. Wei, W. Chen, G. Li, Effect of short-chain organic acids and $\mathrm{pH}$ on the behaviors of pyrene in soil-water system, Chemosphere 81 (2010) 1423-1429.

[39] S.C.G. Teixeira, R.L. Ziolli, M.R.C. Marques, D.V. Pérez, Study of pyrene adsorption on two brazilian soils, Water Air Soil Pollut. 219 (2011) 297-301. 
[40] C.H. Giles, T.H. MacEwan, S.N. Nakhwa, D. Smith, Studies in adsorption. Part XI. A system of classification of solution adsorption isotherms and its use in diagnosis of adsorption mechanisms and in measurement of specific surface areas of solids, J. Soc. Dyers Colourists 74 (1960) 3973-3993.

[41] W.J. Weber Jr., P.M. McGinley, L.E. Katz, A distributed reactivity model for sorption by soils and sediments: 1 . Conceptual basis and equilibrium assessments, Environ. Sci. Technol. 26 (1992) 1955-1962.
[42] I. Heidmann, I. Christl, C. Leu, R. Kretzschmar, Competitive sorption of protons and metal cations onto kaolinite: experiments and modeling, J. Colloid Interf Sci. 282 (2005) 270-282.

[43] P.N. Diagboya, B.I. Olu-Owolabi, K.O. Adebowale, Effects of aging soil organic matter, and iron oxides on the relative retention of lead, cadmium, and copper on soils, Environ. Sci. Pollut. Res. 22 (2015) 10331-10339. 